This is the post-print version of the final paper published in Physiotherapy, 96(2), 169-175, 2010. The published article is available at http://www.sciencedirect.com/science/article/pii/S0031940609001370. Changes resulting from the publishing process, such as peer review, editing, corrections, structural formatting, and other quality control mechanisms may not be reflected in this document. Changes may have been made to this work since it was submitted for publication. Copyright @ 2010 Elsevier B.V.

\title{
Are physiotherapy students adequately prepared to successfully gain employment?
}

\author{
Mandy Jones*, Judith Mclntyre**, Sandra Naylor* \\ ${ }^{*}$ School of Health Science and Social Care, Brunel University \\ **Placement and Careers Centre, Brunel University
}

\section{Introduction}

Following graduation, physiotherapists used to be in an enviable position; vacant posts were plentiful, which allowed new graduates the luxury of selecting the geographical location in which they would like to work and in some instances, the institution [1]. However, over the past few years the situation has completely reversed, with newly qualified physiotherapists experiencing difficulties gaining their first National Health Service (NHS) post [2]. Changes in NHS structure and service delivery, the presence of NHS Trusts with deficit budgets, and the recent economic downturn have lead to a change in the job market, making junior physiotherapy jobs scarce [2, 3-Hunt 2009]. This change in circumstance has led to intense competition for graduate employment (4-Clark 2006), together with the realisation that effective self-marketing is essential in order to secure a junior post. Whilst most undergraduate programmes and the Chartered Society of Physiotherapy (CSP) [5] provide guidance for physiotherapy students regarding making applications for employment, it is becoming increasingly apparent that this area of the undergraduate curriculum must continually evolve to meet the changing requirements of employers (6-Direct Gov UK \& 7-Prospects ref). Limited numbers of jobs have led to over subscription for most advertised junior posts (4-Clark 2006). The number of accepted applications is often capped, leaving graduates disappointed when they are not immediately offered an interview. Even if short-listed, employers are increasingly using pre-interview selection methods, such as written evaluation of clinical knowledge or skills, holding practical assessment days or group interviews. As such, graduates are now required to demonstrate a wide variety of professional and in particular, transferable skills which highlight their strengths and therefore, employability even prior to interview. Transferable skills are defined by the Department for Education \& Employment (8-DfEE 1998) as "those cognitive and personal skills (application of number, communication, information technology, problem-solving, personal skills, 
working with others and improving own learning and performance) which are central to occupational competence in all sectors and at all levels."

At Brunel University, the identification and development of transferable skills are integral to the undergraduate physiotherapy programme. Communication, inter-professional team working, reflective practice, documentation, organisation and self-management skills are all taught and reinforced both academically and clinically throughout the course. Additionally, final year students receive lectures covering the application process; writing curriculum vitae $(\mathrm{CV})$ and personal statement, interview skills, strategies for their continued professional development (CPD) plus information regarding changes to healthcare provision in London. But is this curriculum provision effective in matching current employment demands? (9-Archer). Perhaps more importantly, are students able to recognise and assimilate this information in order to achieve a successful application? Graduate employment is an ongoing issue (10-Hunt, CSP May 2009); however, there is a paucity of physiotherapy literature regarding successful transition into the work place. The overall aim of this research was to establish whether physiotherapy students from a single UK university cohort, were adequately prepared to gain employment. Specifically, to explore student perceptions of the application process, determine how prepared they felt to make job applications and identify what universities can do to facilitate a smooth transition.

\section{Methods}

Following ethical approval from Brunel University, data was collected using two methods; a questionnaire and semi-structured interview. Initially, a pilot questionnaire was formulated following a brain-storming session undertaken by two experienced physiotherapy lecturers and a placement and careers centre consultant. This was completed by a group of 10 final year students and analysed in order to evaluate both clarity and content; where appropriate amendments were made (11-Bell 2005). 87 final year physiotherapy students (both full and part-time), who had completed all taught elements of the course, were invited via email, to voluntarily complete the final questionnaire. The completed questionnaires were returned anonymously to a central collection point. The questionnaire aimed to determine student's perceptions of the employment process and 
specifically how prepared they felt to make job applications to potential employers [11]. Students were asked to answer both open and closed questions which explored their views on the current job situation, the application process and their plans for their first post (appendix 1). The responses $(60 / 87,69 \%)$, from this questionnaire were analysed and subsequently used to identify areas for further in-depth discussion in the interview stage of the research.

Following completion of the questionnaire, an email was sent to all final year students inviting them to attend the interview. 12 respondents volunteered for interview, which lasted a maximum of 1 hour and utilised a semi-structured approach. Although randomly self-selected, the interview group provided a representative sample of the whole cohort (36\% mature, $64 \%$ female, $27 \%$ part-time students). The interviews were undertaken by an experienced interviewer from a nonphysiotherapy background. Each session was digitally recorded and later fully transcribed for analysis. Due care was given to ensure informed consent prior to participation, confidentiality and secure storage of all data.

\section{Analysis}

The closed questions from the survey were analysed and presented using descriptive statistics. Analysis of the open questions illustrated common themes and concerns, which were explored further in the in-depth interview. The primary aim of the research was to explore the students' preparedness to gain employment; therefore an inductive approach to interview analysis was adopted, which is firmly located within the qualitative research paradigm (12-Strauss \& Corbin 1998). An independent researcher from a non-physiotherapy background utilised a systematic approach to analysis; codes, sub-categories and emergent themes arose from the data (13Murphy et al 1998; 14-Hammell et al 2000).

\section{Results}

\section{Questionnaire}

The response rate to the questionnaire was 60/87 (69\%). All respondents completed every question in each section. Data is expressed as a percentage of total response $(X / 60)$; detailed responses are displayed in tables 1 and 2 . 
The questionnaire provided some interesting employment characteristics. $47 \%$ stated that a traditional junior rotation would be their ideal first post, while $26 \%$ wanted any post based in a London teaching hospital. $26 \%$ would only wait six months and $39 \%$ a year to secure their first post; while $71 \%$ would change career, and $99 \%$ would consider working abroad if unsuccessful in securing a UK based post, within their predetermined timeframe.

From an application perspective, 34\% identified a CV and personal statement as the sole criteria for short listing, and $18 \%$ stated an individual interview was the main selection criteria for employment. Perhaps most importantly, students' had difficulties identifying the key skills required for employment as listed on standard person specification; $14 \%$ of students stated a sound knowledge base, and skills such as communication (16\%) and team working (11\%) were essential for employment. However, self management skills such as prioritorisation of clinical caseload ( $0 \%)$, time management $(0 \%)$ and legal documentation $(0 \%)$ were not perceived as essential skills for employment. Furthermore, students had difficulty identifying which key skills were transferable to other aspects of the work place; communication skills (25\%), flexible working $(7 \%)$, team working (5\%), legal documentation (2\%), prioritorisation of a clinical caseload (1\%) and time management skills (1\%), were most frequently listed. Overall, students had limited awareness of the application procedure and the diverse range of pre-interview selection procedures, and as such, underestimated the time and effort required to make a successful application.

\section{Interviews}

The key issues highlighted from analysis of the questionnaire were explored in more depth in the semi-structured interviews. All the interviews were analysed using a thematic approach which revealed several emergent themes. Students felt they received little preparation covering the application process during their undergraduate programme, but gained valuable information about the process from educators whilst on clinical placement. However, there was little consensus from the students as to what they felt employers were looking for in a new graduate. Students had difficulty listing their transferable skills other than communication and team working. They reported 
that verbal and non verbal communication skills were well developed throughout the undergraduate programme, and commended the use of clinical scenarios as an effective way to improve these non-clinical skills, as well as their knowledge base. Interestingly, when asked to identify transferable skills, students drew on previous employment experiences rather than their physiotherapy ones. Students voiced concerns over CPD portfolio preparation, and requested greater input and guidance from the University. Overall, students expressed trepidation towards starting the employment process due to the perceived shortage of junior jobs and an anticipated high level of competition.

\section{Discussion}

Over the last 3 years, UK physiotherapy students have experienced increasing difficulties securing their first post following graduation [3-Hunt 2009; 2]. This is the first study to explore a UK based cohort of physiotherapy students' expectations of the employment process and their preparedness for making a job application. Our key findings were: students could not identify the core or transferable skills required by potential employers; students were unaware of the diverse range of pre-interview selection procedures and underestimated the amount of preparation and effort required to successfully achieve their first physiotherapy post; students wanted more guidance and CPD preparation from the university; students expressed trepidation towards starting the employment process due to the perceived job shortage and anticipated high level of competition.

Despite the wide variety and scope of junior posts available, $47 \%$ of the students canvassed still anticipated undertaking a traditional rotational junior physiotherapy post following graduation, with $26 \%$ specifically wanting to work in a London teaching hospital. This response is perhaps unsurprising, given that the rotational nature of the profession remains embedded within undergraduate training programmes [15-CSP], and that the students participating in this research attended a London university. However, what was surprising was that predominantly due to financial pressures, $26 \%$ of students would only wait six months and $39 \%$ a year to secure their first post. Furthermore, $71 \%$ of students would change career and $99 \%$ would consider working abroad, if unsuccessful in securing a UK graduate post within their identified timeframe. This has 
significant implications for the authorities funding undergraduate physiotherapy education in the UK and the workforce provision necessary to fulfil NHS requirements in the future. The CSP have predicted that in the future there will be an increased demand for physiotherapists, given "the rapidly-aging population and a rise in the number of people with long-term conditions" [16-Moran]. Despite receiving comprehensive education regarding NHS evolution and change, focused around the "Darzi" report [17-Darzi], only $7 \%$ of the students acknowledged employment potential in other health sectors including the community / primary care, social care or private practice. This may simply be reflective of student's individual clinical placement experience, where despite the inclusion of more non-traditional clinical placements, hospital based practice still tends to predominate. Warrinder \& Walker [1] proposed that when identifying the location of a first physiotherapy post, the most influential factors were the attitudes of supervisors and potential colleagues, and the level of in-service training provided. Student perception of these factors is often developed early on during training and consolidated throughout clinical placement experience. Indeed, most students can clearly identify which educators and institutions effectively satisfied their training needs and which did not. In addition, the inclusion of popular or specialist rotations were also cited as important features when selecting potential posts [1], confirming the expectation of undertaking a traditional rotational job. Interestingly, both Atkinson \& Steward [18] and Masters [19] commented that most newly qualified physiotherapists do not believe they have sufficient experience or skills to work in the community immediately following graduation. This may reflect undergraduate programme structure, where community experience may be perceived as a specialist area; however, more significantly, it could be an indication that students do not recognise the transferability of their skills.

In 1997, The Dearing Committee published a report [20] which recommended that key employability or transferable skills should be incorporated into every higher education curriculum. Transferable skills are those, which although learnt in one specific context can easily and successfully be applied to another [8-DfEE; 21-yorke]. Transferable skills can be identified and traced throughout most undergraduate physiotherapy programmes [15-CSP], and provide the generic basis of a person specification for any physiotherapy post. However, the ability to 
recognise and adequately transfer skills is often assumed [21-Yorke]. This is supported by our results, which indicated that not only did students have difficulty identifying the standard criteria required for graduate employment, but few could state which skills were transferable to other aspects of the work place (Table 2). Students were able to identify effective communication, a good knowledge base and team working as essential criteria for employment. This finding was consistent with seminal [22-AGR], and current reports [9-Archer] which state $85 \%$ of employers also consider these professional skills to be important employment factors. However, only $11 \%$ of students were able to isolate team working and $2 \%$ clinical reasoning or problem solving as essential, with leadership identified by less than $1 \%$ of the cohort surveyed. Yet these important capabilities are vital for employment and appear on most physiotherapy job person specifications. The skills most frequently cited as being transferable were again effective communication and "a wide range of clinical experience"; however, clinical experience is physiotherapy specific and therefore, not transferable. Interestingly, some students felt they had to utilise previous employment experiences rather than physiotherapy ones when identifying their transferable skills. This may suggest that some students viewed the skills learnt during the undergraduate programme as clinical or professional, without any differentiation. However, these results also raise the possibility that transferable skills are so integral to undergraduate physiotherapy programme structure that students are unable to identify them in isolation.

This finding is both important and concerning when paralleled with the finding that $34 \%$ of students considered submission of a CV and personal statement as the sole selection criteria for shortlisting. A student's ability to demonstrate physiotherapy specific knowledge and skills is paramount, but not conclusive or alone sufficient to secure employment [21-Yorke]. Nybø [23] reported that individuals were recruited in accordance with the knowledge and skills required by the workplace, to ensure that individual competencies matched the complex challenges of workplace tasks. As such, students must be able to identify and evidence both physiotherapy specific and transferable skills in order to successfully progress through the employment process. 
Universities have an established role in preparing graduates for employment [22-AGR, 24-UGC, 25-White paper, 26-CIHE, 27-CIB, 28-CVCP]. As such, most physiotherapy programmes deliver key elements of inter-professional practice, including preparation for employment within the undergraduate curriculum. However, results of this study indicate that despite the delivery of both generic and specific employment education, students felt they received little preparation for making job applications during their training. Interestingly, they believed that they gained more valuable information whilst on clinical placement. The benefits of clinical education have been well recognised; communication and interpersonal competencies within health and social care teams are usually learned and assimilated through on-the job training [29-Duffy]. In addition, students are provided with a holistic approach to their work, facilitating standardisation of their skills, which aids the development of both self-confidence and self-belief [30 NAO, 31-Hilton]. Mason et al [32] suggested that the positive correlation between work experience and employability reinforces that essential transferable skills are predominantly learnt in the workplace. There may be a misconception amongst students that because university tutors are not primarily working in a clinical forum, they are unaware of current issues surrounding the job market. Students valued the transfer of information from their peers more highly than the formal employment preparation they received in the classroom; however, despite this, they were still unable to provide a consensus as to what is required by employers from a new graduate.

Students voiced concerns over CPD portfolio preparation, as they perceived evidence of CPD as essential for employment. They wanted the university to provide more structured guidance covering CPD portfolio formation and use throughout the undergraduate programme. Interestingly, this area of the curriculum was instigated at the beginning of the second year of study and subsequently reinforced throughout the programme. Students were provided with a lecture covering portfolio preparation and were issued with the CSP portfolio guide in CD-Rom format plus supporting literature $(33,34,35$-CSP 2005). It has been suggested that because this area of the curriculum is not formally examined, it was given low priority (36-Snadden \& Thomas 1998; 37Pearson \& Heywood 2004; 38-Grant et al 2006) by students until they approached graduation and impending employment. 
Our data suggest that students underestimated the amount of preparation and effort required to successfully achieve their first physiotherapy post. This was something of a paradox, as participation in the study and in particular the interview, was voluntary and was therefore by definition populated by a self-selecting group of more motivated students. Indeed, $82 \%$ of this group achieved a 2:1 or $1^{\text {st }}$ class honours degree. However, despite academic success, these high achieving students were unaware of the potential hurdles involved in the employment process.

\section{Recommendations}

Accepting that this was a cohort from a single UK university, our results imply that despite completing a curriculum containing formalised education, final year physiotherapy students were unprepared to successfully gain employment. This was an interesting and surprising outcome as this area of undergraduate programme appeared to be effectively fulfilled. However, the impact of the changing economic climate on graduate employment has necessitated a change of emphasis in undergraduate curriculum delivery. Although our results are not wholly transferable, elements of our findings may be applicable to other qualifying institutions. In light of these findings, the physiotherapy programme at Brunel University has been reviewed. Most importantly, transferable skills will be re-established as such, allowing their transparent application to be identified and developed throughout the curriculum in both a clinical and non-clinical context. Emphasis on the importance of adequately demonstrating these skills and discussion of pre-interview selection methods will be formally introduced in the final year. CPD portfolio formation will be structured and facilitated with the instigation of a reflective practice proforma, which will be completed by students following each clinical and theoretically based teaching block. The proforma will provide them with an effective self-evaluation tool and comprehensive documentation of their developing knowledge and skills. Students are already encouraged to access and utilise electronically-based portfolios as a progressive and easily accessible way to identify, document and evidence CPD.

The results of this study have prompted amendments to the curriculum in response to student needs, but this process of reflection and re-evaluation must be continual. It is crucial to monitor 
which skills and attributes employer's prioritorise, in order to develop and educate students to match their expectations; indeed employer involvement in curriculum design has an independent positive effect on graduate employment [31-Mason]. Once the goals are firmly established, collaborative working with university careers advice centres maximises the potential of students by providing a wealth of guidance and expertise through each stage of the application process. It is unrealistic for students to expect to be successful at interview solely on the basis of providing evidence-based clinically competent answers. They must learn to evidence both clinical and transferable skills, incorporating key elements highlighted in the job or person specification. However, although universities can provide focussed support, students must also acknowledge responsibility for employment preparation [39-CSP], which includes learning about the selection process and all that involves.

The constant evolution and growth of the NHS requires the physiotherapy graduate to be equipped with a multitude of transferable skills which can be applied to any given situation. Many are integral to the profession itself and synonymous with the core undergraduate curriculum. However, analysis and assimilation of these skills cannot be assumed. Changes in employment culture now demand that universities reflect on their curriculum content and delivery to deconstruct the hidden elements of the programme in order to produce graduates who meet employer's expectations and make a smooth transition into the workplace.

Conflict of Interest Statement: None

\section{References}

1. Warrinder JM. \& Walker AM. (1996) Factors affecting physiotherapy graduate job selection Physiotherapy May;82(5):291-4

2. CSP Graduate Employment Bulletin (2008) available at www.csp.org.uk/director/newsandevents/physioalerts.cfm?item id=34960C09C

3. Louise Hunt News and Analysis CSP website / Frontline $2^{\text {nd }}$ September 2009 
4. Tim Clark The Guardian, Tuesday 5 December 2006 All trained up and nowhere to go:

Physiotherapists and nurses are having to change direction as NHS jobs dry up http://www.guardian.co.uk/society/2006/dec/05/health.postgraduate

5. CSP Information Paper STU13: (2007) Survival Guide in Obtaining your first Physiotherapy Post

6. http://careersadvice.direct.gov.uk/features/transferable_skills.htm Accessed $8^{\text {th }}$ Sept 2009

7. http://www.prospects.ac.uk/cms/ShowPage/Home page/What do graduates do 2008/What do employers want /p!ebfpppd Accessed 8th Sept 2009

8. Law Discipline Network: General transferable skills report - DfEE 1998 London Available from http://www.ukcle.ac.uk/resources/ldn/index.html

9. Archer W. \& Davison J. (2008) Graduate Employability: What do employers want? The Council for Industry and Higher Education. Graduate Employment $25^{\text {th }}$ February

10. Louise Hunt News and Analysis CSP website / Frontline 20 May 2009

11. BELL, J., 2005 Doing your research project: a guide for first-time researchers in education, health and social science 4th ed. Maidenhead Open University Press.

12. STRAUSS, A.L., CORBIN, J., 1998. Basics of qualitative research. 2nd Ed. London. Sage.

13. MURPHY, E., DINGWALL, R., GREATBATCH, D., PARKER, S. and WATSON, P., 1998. Qualitative research methods in health technology assessment: a review of the literature. Health Technology Assessment, 2(16).

14. HAMMELL, K.W., CARPENTER, C and I. DYCK, eds, Using qualitative research. A practical introduction for occupational and physical therapists. London: Churchill Livingstone, pp. 59-72.

15. CSP (2002) Curriculum Framework for qualifying programmes in physiotherapy available at http://www.csp.org.uk/uploads/documents/CFforQPP.pdf

16. Moran, K. (2009) Brighter picture on graduate jobs. Frontline Vol 15 No 1 6-7

17. Prof Lord Darzi (2007) A Case for Change - Healthcare for London: A framework for action NHS London available at http://www.healthcareforlondon.nhs.uk/

18. Atkinson K. \& Stewart B. (1997) A longitudinal study of occupational therapy new practitioners in their first years of professional practice: preliminary findings. British Journal of Occupational Therapy, August 60(8) 
19. Masters P. (2004) Working Out: Developing the London Workforce. Supporting London's New Graduate Physiotherapy Increase. London SELWDC

20. Dearing, R. (1997) The Dearing Report: National Committee of Inquiry into Higher Education. Higher Education in the Learning Society. London. HMSO.

21. Yorke M. (2006) Employability in higher education: What it is - What it is not Learning \& Employability series 1 York, The Higher Education Academy

22. Association of graduate recruiters (AGR), (1995) Skills for Graduates in the $21^{\text {st }}$ Century Cambridge AGR

23. Nybø G. (2004) Personnel development for dissolving jobs: towards a competency- based approach? International Journal of Human Resource Management 15:3 May 2004 549-564 Taylor \& Francis Ltd; Norway

24. University Grants Committee. (1984) A strategy for Higher Education into the 1990s: The University Grants Committee's Advice. London: Her Majesty's Stationary Office. UK

25. White Paper (1987) Higher Education: Meeting the Challenge. Her Majesty's Stationary Office UK

26. Council for Industry and Higher Education (CIHE) (1996). Helping Students Towards Success at Work: Declaration of Intent. London: CIHE.

27. Confederation of British Industry (CBI) (1994). Thinking Ahead: Ensuring the Expansion of Higher Education in the 21st Century. London: CBI.

28. Committee of Vice Chancellors and Principals of the Universities of the United Kingdom (CVCP), 1998, Skills Development in Higher Education (London, CVCP).

29. Duffy F.D., Gordon G.H., Whelan G., Cole-Kelly K., Frankel R. (2004) Assessing Competence in Communication and Interpersonal Skills: The Kalamazoo 11 Report Academic Medicine Vol.79, No6, June 2004

30. National Audit Office 2001 Educating \& training the future health professional workforce for England. Norwich: The Stationery Office Ltd

31. Hilton R. \& Morris J. (2001) Student Placements - is there evidence supporting team skill development in clinical practice? Journal of Interprofessional Care; Vol 15. No 2 pgs. 171-183. Taylor \& Francis Ltd. UK. 
32. Mason G., Williams G., Crammer S. (2006) Employability Skills Initiatives in Higher Education: What Effects Do They Have On Graduate Labour Market Outcomes?

33. CSP July 2005 Information paper: Learning and Development. CPD6

34. CSP October 2005 Information paper: Resources for Continuing Professional Development (CPD). CPD11

35. CSP July 2005 Information paper: The CPD Process. CPD30

36. Snadden, D. \& Thomas, M.L. 1998, "Portfolio learning in general practice vocational training Does it work?", Medical education, vol. 32, no. 4, pp. 401-406.

37. Pearson, D.J. \& Heywood, P. 2004, "Portfolio use in general practice vocational training: a survey of GP registrars", Medical education, vol. 38, no. 1, pp. 87-95.

38. Grant, A.,P, Metcalf, E., Pill, E. \& Houston, H. 2006b, "Students' views on reflective learning techniques:an efficacy studey at a UK medical school", Medical Education, vol. 40, no. 4, pp. 379-388.

39. CSP (2005) Core Standards of Physiotherapy Practice available at http://www.csp.org.uk/director/members/libraryandpublications/csppublications.cfm?item id=74 C874E8BF4D05D6DA275134D82A846D 